\title{
RT-PCR Differentiation, Molecular and Pathological Characterization of Andean and Ordinary Strains of Potato virus $S$ in Potatoes in China
}

Jinghui Wang, Fanye Meng, Ruhao Chen, and Jun Liu, MOE Key Laboratory of Horticultural Plant Biology, National Center for Vegetable Improvement, Potato Engineering and Technology Research Center of Hubei Province, and Huazhong Agricultural University, Wuhan 430070, China; Xianzhou Nie, Potato Research Center, Agriculture and Agri-Food Canada, Fredericton, New Brunswick E3B4Z7, Canada; and Bihua Nie, MOE Key Laboratory of Horticultural Plant Biology, National Center for Vegetable Improvement, Potato Engineering and Technology Research Center of Hubei Province, and Huazhong Agricultural University, Wuhan 430070, China

\begin{abstract}
Wang, J., Meng, F., Chen, R., Liu, J., Nie, X., and Nie, B. 2016. RT-PCR differentiation, molecular and pathological characterization of Andean and ordinary strains of Potato virus $S$ in potatoes in China. Plant Dis. 100:1580-1585.

A survey of potatoes in a field in Hubei, China, for common potato viruses revealed that Potato virus $S$ (PVS) was the most abundant virus. To unveil the strain identity of the virus, primers specific to the ordinary and/or Andean strains of PVS (i.e., $\mathrm{PVS}^{\mathrm{O}}$ and $\mathrm{PVS}^{\mathrm{A}}$ ) were designed. RTPCR using these primers successfully detected $\mathrm{PVS}^{\mathrm{O}}$ and $\mathrm{PVS}^{\mathrm{A}}$ in the samples. Sequence analysis of the amplicons confirmed the correctness of the RT-PCR assay. Two isolates, PVS HB24 and PVS HB7, representing $\mathrm{PVS}^{\mathrm{O}}$ and $\mathrm{PVS}^{\mathrm{A}}$, respectively, were chosen for molecular and biological characterization. Both isolates contained a genome of $8,453 \mathrm{nt}$ in length with six open reading frames. They shared a sequence identity

of $79.5 \%$ at the complete genome sequence level. Phylogenetic analysis placed PVS HB24 and PVS HB7 to $\mathrm{PVS}^{\mathrm{O}}$ and $\mathrm{PVS}^{\mathrm{A}}$ clades, respectively. PVS HB24 induced chlorotic local lesions on the inoculated leaves but no visible symptom on the upper uninoculated leaves of Chenopodium quinoa after mechanical inoculation, whereas PVS HB7 induced both local and systemic symptoms on $C$. quinoa. ELISA and RT-PCR confirmed that PVS HB7 infected $C$. quinoa systemically whereas PVS HB24 failed to do so. Both isolates infected potato cv. Shepody and Solanum chacoense asymptomatically, but did not infect Nicotiana occidentalis and N. tobaccum cv. Samsun.
\end{abstract}

Potato virus $S$ (PVS, genus Carlavirus, family Betaflexiviridae), is one of the most common viruses infecting potato crops worldwide (Adams et al. 2004). The virus has 610 to $700 \mathrm{~nm}$ long filamentous particles containing a single stranded positive sense RNA genome of approximately 8.4 to $8.5 \mathrm{~kb}$, with a $5^{\prime}$ cap structure, six open reading frames (ORFs), and a 3' poly(A) tail (Lin et al. 2014; Mackenzie et al. 1989; Matoušek et al. 2005). PVS can be transmitted by plant contact and by several aphid species in a nonpersistent manner (Franc and Banttari 1996; Kerlan 2008; MacKinnon 1974; Wardrop et al. 1989). The virus generally induces inconspicuous symptoms in many potato cultivars. However, it can cause vein deepening, leaf rugosity, mottling, early defoliation, and/or plant death, depending on potato cultivars and virus isolates, and leads to yield reductions of up to 10 to $20 \%$ (Cox and Jones 2010; Dolby and Jones 1987; German 2001; Lin et al. 2014).

Two distinct strains, i.e., ordinary strain $\left(\mathrm{PVS}^{\mathrm{O}}\right)$ and Andean strain $\left(\mathrm{PVS}^{\mathrm{A}}\right)$, have been recognized based on biological and molecular properties (Cox and Jones 2010; Foster 1991; Foster and Mills 1992; Jones 1981; Matoušek et al. 2005). Upon mechanical inoculation, $\mathrm{PVS}^{\mathrm{A}}$ infects Chenopodium quinoa systemically whereas $\mathrm{PVS}^{\mathrm{O}}$ induces local lesions but cannot infect the plant systemically (Cox and Jones 2010; Kerlan 2008). PVS ${ }^{\mathrm{A}}$ shares approximately $80 \%$ sequence identity with $\mathrm{PVS}^{\mathrm{O}}$ (Duarte et al. 2012), and can be serologically differentiated by monoclonal antibodies specific to the strains (Čeřovská and Filigarova 1995). Nevertheless, several divergent variants

Corresponding author: Bihua Nie, Email: nbihua@mail.hzau.edu.cn

The nucleotide sequence data reported in this paper have been submitted to GenBank and have been assigned the accession numbers KU896945 and KU896946.

*The $\boldsymbol{e}$-Xtra logo stands for "electronic extra" and indicates that three supplementary tables and three supplementary figures are available online.

Accepted for publication 9 March 2016.

http://dx.doi.org/10.1094/PDIS-11-15-1257-RE

(C) 2016 The American Phytopathological Society of PVS termed PVS ${ }^{\mathrm{O}-\mathrm{CS}}$ (ordinary and Chenopodium systemic), which infected $C$. quinoa systemically but phylogenetically clustered closely to $\mathrm{PVS}^{\mathrm{O}}$, were reported (Lambert et al. 2012; Matoušek et al. 2005), suggesting an incongruity between biological and sequence properties in PVS.

Although PVS is thought to be widespread in China (Li et al. 2013; Wang et al. 2011), little is known about its genetic background or biological and molecular properties, and moreover, the lack of efficient tools limits the intention to investigate the strain status of PVS in the country. The objectives of this study were: i) to develop an RT-PCR based method for PVS strain differentiation by using strain-specific primers, ii) to test the newly developed method using PVS samples collected in a potato field, and iii) to unveil and characterize the molecular and biological properties of Chinese isolates of $\mathrm{PVS}^{\mathrm{O}}$ and/or $\mathrm{PVS}^{\mathrm{A}}$.

\section{Materials and Methods}

Virus samples collection and ELISA. One hundred and fifteen tubers were randomly collected from nine potato advanced clones in adjacent potato field plots in Hubei, China, in 2012. These tubers were tested for the presence of PVS, Potato virus $Y$ (PVY), Potato leafroll virus (PLRV), Potato virus $X$ (PVX), Potato virus A (PVA), and Potato virus $M$ (PVM) by double-antibody sandwich (DAS)ELISA with virus-specific antibodies (Agdia, Elkhart, IN) according to the manufacturer's guidelines. Three drops $(\sim 100 \mu \mathrm{l})$ of tuber sap obtained by a tuber slicer (Electrowerk, Behcke and Co, Hannover, Germany) were used for the ELISA assay. The absorbance at $405 \mathrm{~nm}$ $\left(\mathrm{A}_{405}\right)$ was recorded using an ELx800 Universal Microplate Reader (Bio-Tek Instruments Inc., Winooski, VT). The positive control was provided and used according to the instructions of the manufacturer (Agdia), the sap from mock inoculated healthy plants was used as the negative controls, and the blanks were adjusted using the substrate solution. Samples were considered positive when $\mathrm{A}_{405}$ was at least four times greater than that of the negative controls.

PVS positive tubers were planted in $20 \mathrm{~cm}$ pots containing premixed soil and the resulting plants were grown in a greenhouse at Huazhong Agriculture University at 20 to $25^{\circ} \mathrm{C}$ for further investigation.

Reverse transcription (RT)-PCR for differentiation of PVS and PVS ${ }^{\mathbf{A}}$. Total RNA was extracted from fresh leaf samples using 
PLANTpure plant RNA Kit (Aidlab Biotechnologies Co., Ltd, Beijing, China). The first-strand cDNA was synthesized by using an oligo dT(18) primer and HiScript Reverse transcription (Vazyme Biotech Co., Ltd, Nanjing, China) according to the manufacturer's instructions. RT was carried out at $50^{\circ} \mathrm{C}$ for $45 \mathrm{~min}$.

Two duplex-PCRs targeted the coat protein (CP) gene and ORF1 were performed using appropriate primers (Table 1 and Supplementary Fig. S1). For PVS ${ }^{\mathrm{A}}$-like isolates, a 759-bp CP fragment and a 449-bp ORF1 fragment were anticipated to be amplified by the two PCR assays, respectively. Similarly, a 489-bp CP amplicon and a 320-bp ORF1 amplicon were expected to be multiplied for $\mathrm{PVS}^{\mathrm{O}}$-like isolates, respectively. For recombinant isolates resembling Vltava, the 759-bp $\mathrm{PVS}^{\mathrm{A}}$-specific CP fragment and the 320-bp $\mathrm{PVS}^{\mathrm{O}}{ }_{\text {-specific }}$ ORF1 fragment were predicted to be produced by the two PCR assays, respectively. For RVC and similar isolates, which do not belong to $\mathrm{PVS}^{\mathrm{A}}$ and $\mathrm{PVS}^{\mathrm{O}}$, no amplification was anticipated in both duplex PCR assays due to multiple nucleotide mismatches with the primers. Nevertheless, in combination with ELISA, all the groups (i.e., $\mathrm{PVS}^{\mathrm{O}}$, PVS $^{\mathrm{A}}$, Vltava-like, and RVC-like) should be discriminated.

The amplification was conducted in a volume of $25 \mu l$ containing $2 \mu \mathrm{l}$ aliquots of the cDNA mixture, $10 \mathrm{mM}$ Tris- $\mathrm{HCl}, \mathrm{pH} 8.3,50 \mathrm{mM}$ $\mathrm{KCl}, 1.5 \mathrm{mM} \mathrm{MgCl}_{2}, 100 \mu \mathrm{M}$ each of dNTPs, $0.1 \mu \mathrm{g}$ each of the sense and antisense primers, and 0.625 units of TaqDNA polymerase (CWBIO, Beijing, China). The PCR assay was performed on a C1000 Thermal Cycler (Bio-Rad Laboratories, Hercules, CA) for 35 cycles with DNA denaturing at $95^{\circ} \mathrm{C}$, primer annealing at $58^{\circ} \mathrm{C}$, each for $30 \mathrm{~s}$, and primer extension at $72^{\circ} \mathrm{C}$ for $45 \mathrm{~s}$. A final step of $10 \mathrm{~min}$ at $72^{\circ} \mathrm{C}$ was also included. A total of $8 \mu \mathrm{l}$ of the amplification product was fractionated by electrophoresis on $1.2 \%$ agarose gel containing $0.5 \mu \mathrm{g} / \mathrm{ml}$ ethidium bromide and photographed under UV illumination with a Universal Hood II (Bio-Rad Laboratories, Segrate, Italy).

Complementary DNA cloning and sequencing. One isolate from each of $\mathrm{PVS}^{\mathrm{O}}$ and $\mathrm{PVS}^{\mathrm{A}}$ groups based on the above mentioned RT-PCR assay was chosen for determination of the complete genome sequence. To achieve this, high quality total RNA was extracted from leaves of PVS-infected potato plants using the $\mathrm{LiCl}$ procedure as described previously (Mohapatra et al. 1987). The cDNA was synthesized as described above. RT-PCR-based cloning was performed using three sets of primers that span the entire PVS genome (for primer sequences, polarities, and approximate locations, see Table 1). Each primer pair was projected to result in a DNA fragment of 2.5 to $3.1 \mathrm{~kb}$, overlapping with adjacent fragments by approximately $100 \mathrm{bp}$ at each end.

Phanta Super-Fidelity DNA polymerase (Vazyme Biotech Co., Ltd, Nanjing, China) was used to amplify the target PVS fragment. A varying annealing temperature regime $\left(58^{\circ} \mathrm{C}\right.$ for the first 10 cycles, $56^{\circ} \mathrm{C}$ for the next 10 cycles, $54^{\circ} \mathrm{C}$ for the following 15 cycles) was employed in the PCR to ensure the amplification efficiency.

The putative PVS amplicons were separated on a 1.2\% agarose gel and extracted from the gel using an AxyPrep DNA Gel extraction kit
(Axygen Scientific, Inc., USA). Purified fragments were cloned into a pEASY-Blunt Cloning Kit (TransGen Biotech, Beijing, China) according to the manufacturer's instructions. Seven cDNA clones of each fragment were sent to Sangon Biotech Co., Ltd. (Shanghai, China) for sequencing. Each isolate was fully sequenced twice, and identical results were obtained. Sequence identities and alignments of these isolates with various potato virus species were analyzed using BLAST and Clustal Omega (http://www.ebi.ac.uk/Tools/msa/ clustalo/). MEGA6 was employed to analyze the phylogeny of PVS isolates with the neighbor-joining method using the complete genome sequences or CP genes(Tamura et al. 2013).

Mechanical inoculation of indicator plant. To determine the pathological properties of various PVS isolates, seedlings/plantlets of several plant species including C. quinoa, Nicotiana occidentalis, N. tobacum (cv. Samsun), Solanum chacoense, and S. tuberosum (cv. Shepody) were planted in greenhouse at 20 to $25^{\circ} \mathrm{C}$. Five plants of each species at the 6 to 8 leaf stage were inoculated with each PVS inocula (leaf extract: $1 \mathrm{~g}$ leaf tissue homogenized in $0.1 \mathrm{M}$ potassium phosphate buffer, $\mathrm{pH}$ 7.6) by mechanical wounding as described by Singh et al. (2003). Five plants inoculated with buffer served as the healthy (mock) control. Symptom development in the plants was recorded at 3-day intervals for 4 weeks on the inoculated and upper uninoculated leaves. DAS-ELISA and RT-PCR were conducted to test for PVS on the inoculated and/or the upper uninoculated leaves at 28 days post inoculation (dpi).

\section{Results}

Common potato viruses in field potatoes. Of the six viruses tested, except PVA and PVX, the other four viruses (PVY, PVS, PLRV, PVM) were readily detected in the samples with an occurrence at 54/115 (47.0\%) for PVS, 33/115 (28.7\%) for PLRV, $18 / 115$ (15.7\%) for PVY, and 17/115 (14.8\%) for PVM. Moreover, PVS was the only virus that was detected in all nine advanced breeding clones with an occurrence ranging from 37.5 to $100 \%$, while PLRV, PVY, and PVM were detected in seven, three, and eight advanced breeding clones, respectively. These results indicate that PVS was the most common virus in the samples, and an investigation into the molecular and pathological properties of the virus in the samples was thus warranted.

Development of RT-PCR for PVS strain differentiation. Although PVS $^{\mathrm{A}}$-strain-specific monoclonal antibody has been developed (Čeřovská and Filigarova 1995), it is unavailable in China and thus unable to specify strain-type for the PVS isolates found in the samples. To mend this gap, $\mathrm{PVS}^{\mathrm{O}}$ and $\mathrm{PVS}^{\mathrm{A}}$ specific primers were selected upon alignment of the available full length sequences of PVS, and two duplex RT-PCR assays were developed for detection and differentiation of PVS strains/strain groups. Subsequently, all the 54 PVS-ELISA positive samples were subjected to the RTPCR assays to test the efficacy of the primers. Excitingly, both $\mathrm{PVS}^{\mathrm{O}}$ - and $\mathrm{PVS}^{\mathrm{A}}$-specific fragments were amplified successfully by respective strain specific primers in the assays (Fig. 1). For the

Table 1. Primers designed for differentiation of ordinary and Andean strains of Potato virus $S$ (PVS) and for cloning and sequencing of the complete genomic sequences of PVS

\begin{tabular}{|c|c|c|}
\hline Name & Sequence & \\
\hline PVS-A7228s & 5' AGATCCTTCTAGTTCAGGGGAAG 3' & Match with the $\mathrm{PVS}^{\mathrm{A}}$-like $\mathrm{CP}$ genes \\
\hline PVS-A7986a & 5' GCCAT GCTCTTGTGAGCGTTA 3' & \\
\hline PVS-O7577s & 5' GCTGACATCGCTGGACTTGGG 3' & Match with the $\mathrm{PVS}^{\mathrm{O}}$-like $\mathrm{CP}$ genes \\
\hline PVS-O8065a & 5' ATCTCAGCGCCAAGCATCCCT 3' & \\
\hline PVS-A2579s & 5' CTAGATTCTGCAGTGGGGATTGA 3' & Match with the PVS ${ }^{\mathrm{A}}$-like ORF1 \\
\hline PVS-O2708s & 5' GGCAAGTGCCCTGCAGCAA 3' & Match with the PVSO-like ORF1 \\
\hline PVS-3027a & $5^{\prime}$ TGGTATAGAACCATGGACTGCAC $3^{\prime}$ & Work with PVS-A2579s and PVS-O2708s \\
\hline PVS-0007s & 5' CACTCCCGAAAATAATTTGACTTAAAC 3' & For the first fragment cloning \\
\hline PVS-3057a & $5^{\prime}$ GGCAAAGCTGCCTCAAAGTG $3^{\prime}$ & \\
\hline PVS-2923s & 5’ AAGTAAGCARTACCGGTACAGGAT 3’ & For the second fragment cloning \\
\hline PVS-6013a & 5' ATACTACTAAGCTGATTACCTAAGCT 3' & \\
\hline PVS-5879s & 5' CGCATGTCAGAGGAGGAACT $3^{\prime}$ & For the third fragment cloning \\
\hline PVS-8455a & $5^{\prime}$ TTCTTTATAGTTGCACACTTATATATTAT $3^{\prime}$ & \\
\hline
\end{tabular}


duplex RT-PCR targeting the $\mathrm{CP}$ gene, $\mathrm{PVS}^{\mathrm{A}}$-specific fragment of $\sim 759$ bp was amplified in samples 1 to 7,9 to 12 , and 16; and the $\mathrm{PVS}^{\mathrm{O}}$-specific fragment of $\sim 489$ bp was amplified in samples 1,2 , 8, 12 to 15, and 17 (Fig. 1A). Identical results were obtained in the duplex RT-PCR targeting ORF1 (Fig. 1B), $\mathrm{PVS}^{\mathrm{A}}$-specific fragment of $\sim 449$ bp was amplified in samples 1 to 7,9 to 12 , and 16; and the $\mathrm{PVS}^{\mathrm{O}}$-specific fragment of $\sim 320 \mathrm{bp}$ was amplified in samples $1,2,8$, 12 to 15 , and 17 . In samples 1,2 , and 12 , both $\mathrm{PVS}^{\mathrm{A}}$ - and $\mathrm{PVS}^{\mathrm{O}}{ }_{-}$ specific fragments were amplified, indicating mixed $\mathrm{PVS}^{\mathrm{O}}$ and $\mathrm{PVS}^{\mathrm{A}}$ infections in the samples. To confirm the correctness of the assays, six representative amplicons for each of the four type of strain-specific fragments, total 24 amplicons from $3 \mathrm{PVS}^{\mathrm{A}}, 3 \mathrm{PVS}^{\mathrm{O}}$, and 3 mixed infected samples, were cloned and sequenced. As shown in Figure $1 \mathrm{C}$, the projected PVS ${ }^{\mathrm{A}}$ amplicons (CP, $759 \mathrm{bp}$; ORF1, $449 \mathrm{bp}$ ) exhibited a sequence identity of 96.1 to $97.2 \%$ and 93.8 to $95.8 \%$ with the respective genome region of $\mathrm{PVS}^{\mathrm{A}}$ isolate $\mathrm{BB}-\mathrm{AND}$, and 82.8 to $83.8 \%$ and 74.6 to $78.8 \%$ with the respective genome region of $\mathrm{PVS}^{\mathrm{O}}$ isolate WaDef-US. Contrary to that, the projected $\mathrm{PVS}^{\mathrm{O}}$ amplicons (CP, $489 \mathrm{bp}$; ORF1, $320 \mathrm{bp}$ ) showed a sequence identity of 95.3 to $98.0 \%$ and 95.4 to $99.1 \%$ with $\mathrm{PVS}^{\mathrm{O}}$ isolate WaDef-US/Yunnan, and 83.7 to $85.1 \%$ and 76.7 to $79.1 \%$ with PVS $^{\mathrm{A}}$ isolate BB-AND. These results thus confirmed the accuracy of the PCR assays. Of the 54 PVS-ELISA positive samples, 34 (63.0\%) and 16 (29.6\%) were infected singly with $\mathrm{PVS}^{\mathrm{A}}$ and $\mathrm{PVS}^{\mathrm{O}}$ respectively, and 4 (7.4\%) were infected with both $\mathrm{PVS}^{\mathrm{A}}$ and $\mathrm{PVS}^{\mathrm{O}}$. One representative isolate from each of PVS ${ }^{\mathrm{A}}$ and $\mathrm{PVS}^{\mathrm{O}}$ strain groups, designated as PVS HB7 and PVS HB24 respectively, was selected for further characterization.

Sequence characterization of two PVS isolates. Both the PVS HB7 and PVS HB24 isolates contained a genome of 8,453 nt in length, excluding poly(A) (Table 2). Six ORFs were found in both isolates, consistent with other PVS isolates report to date. The ORF1 (nt. 57 to 5,984) encoded a 1,975-amino-acid-long putative RNAdependent RNA polymerase (RdRp); ORF2 to ORF4 (nt. 5,971 to 6,702 ; nt. 6,680 to 7,006 ; nt. 6,970 to 7,170 ) were the triple gene block (TGB), encoding TGB proteins (TGBp) 1 to 3 of 243, 108, and 66 amino acid in length, correspondingly; ORF5 (nt. 7,212 to 8,096) encoded the 294 amino acid-long coat protein (CP); and ORF6 (nt. 8,093 to 8,377) encoded a putative nucleic acid binding protein (NABP) 94 amino acid in length. The two isolates shared a sequence identity of $79.5 \%$ at the complete genome sequence level. For each ORF, the identity varied, ranging from 77.9 to $86.1 \%$ (Table 2). Correlatively, amino acid sequence identities for the proteins encoded by the ORFs were from 79.8 to $97.2 \%$, with the NABP being the lowest (79.8\%) and the TGBp2 the highest $(97.2 \%)$.

Further comparison of the newly obtained PVS sequences with other complete genome sequences retrieved from databases was performed. PVS HB7 shared $96.5 \%$ sequence identity with BB-AND, a PVS $^{\mathrm{A}}$ isolate in Brazil (Duarte et al. 2012), and 95.2\% identity with

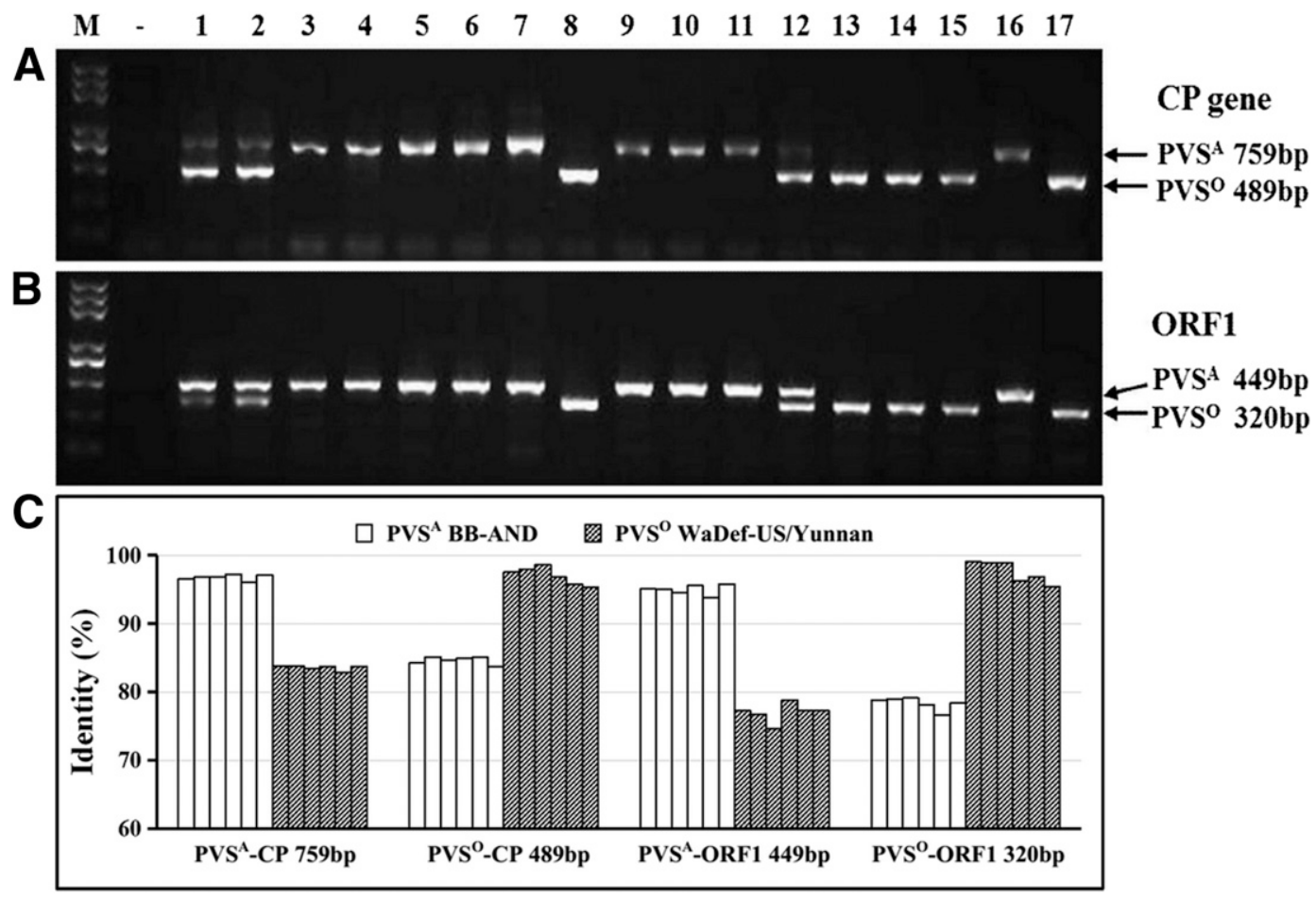

Fig. 1. RT-PCR assay for genotyping PVS isolates. A, Duplex RT-PCR for differentiating Andean and ordinary strains of Potato virus S (PVS) based on CP gene. B, Duplex RT-PCR for differentiating Andean and ordinary strains of PVS based on ORF1. Lanes 1 to 17, PVS-ELISA positive samples; -, negative control; M, Trans2K Plus DNA Marker (TransGen Biotech Co., Ltd, Beijing, China, from top to bottom: 5,000, 3,000, 2,000, 1,000, 750, 500, 250, and 100 bp). C, Sequence identities between PCR amplicons and PVS ${ }^{A}$ isolate BBAND and PVS ${ }^{O}$ isolate WaDef-US/Yunnan.

Table 2. Genome organization and sequence identity of Potato virus S (PVS) isolates HB7 and HB24

\begin{tabular}{|c|c|c|c|c|c|c|c|c|c|c|c|c|c|c|c|}
\hline \multirow[b]{2}{*}{ Isolate } & \multirow{2}{*}{$\begin{array}{c}\begin{array}{c}\text { Complete Seq. } \\
\text { (nt. 1-8,543) }\end{array} \\
\text { nt }\end{array}$} & \multirow{2}{*}{$\begin{array}{c}\begin{array}{c}5^{\prime} \text { UTR } \\
\text { (nt. 1-56) }\end{array} \\
\text { nt }\end{array}$} & \multicolumn{2}{|c|}{$\begin{array}{c}\text { ORF1 } \\
\text { (RdRp) } \\
\text { (nt. 57-5,984) }\end{array}$} & \multicolumn{2}{|c|}{$\begin{array}{c}\text { ORF2 } \\
\text { (TGB1) } \\
\text { (nt 5,971- } \\
6,702)\end{array}$} & \multicolumn{2}{|c|}{$\begin{array}{c}\text { ORF3 } \\
\text { (TGB2) (nt. } \\
\text { 6,680-7,006) }\end{array}$} & \multicolumn{2}{|c|}{$\begin{array}{c}\text { ORF4 } \\
\text { (TGB3) } \\
\text { (nt. 6,970- } \\
\text { 7,170) }\end{array}$} & \multicolumn{2}{|c|}{$\begin{array}{c}\text { ORF5 (CP) } \\
\text { (nt. 7,212- } \\
\text { 8,096) }\end{array}$} & \multicolumn{2}{|c|}{$\begin{array}{c}\text { ORF6 } \\
\text { (NCBP) } \\
\text { (nt. 8,093- } \\
\text { 8,377) }\end{array}$} & \multirow{2}{*}{$\begin{array}{c}\begin{array}{c}\text { 3'UTR }^{\prime} \text { UTR } \\
\text { (nt. 8,378-8,453) }\end{array} \\
\text { nt }\end{array}$} \\
\hline & & & nt & $\mathbf{a a}$ & nt & $\mathbf{a a}$ & nt & $\mathbf{a a}$ & nt & $\mathbf{a a}$ & nt & $\mathbf{a a}$ & nt & $\mathbf{a a}$ & \\
\hline HB7 & 8,543 & 56 & 5,928 & 1,975 & 732 & 243 & 327 & 108 & 201 & 66 & 885 & 294 & 285 & 94 & 77 \\
\hline HB24 & 8,543 & 56 & 5,928 & 1,975 & 732 & 243 & 327 & 108 & 201 & 66 & 885 & 294 & 285 & 94 & 77 \\
\hline Identify (\%) & 79.5 & 98.2 & 77.9 & 85.8 & 86.1 & 94.7 & 82.9 & 97.2 & 83.1 & 89.4 & 80.9 & 94.2 & 80.0 & 79.8 & 86.8 \\
\hline
\end{tabular}


RL5, a Colombian PVS ${ }^{\mathrm{A}}$ isolate in GenBank (JX 683388). Nevertheless, the identities between $\mathrm{HB} 7$ and $\mathrm{PVS}^{\mathrm{O}}$ strains fell to 79.2 to $80.2 \%$. In contrast, PVS HB24 shared high identities with various PVS $^{\mathrm{O}}$ strains, including North American isolates Id4106-US (97.7\%) and WaDef-US (97.7\%), European isolates 89.249 (92.5\%) and Leona (93.9\%), and Australian isolate SW-14 (94.5\%) and Chinese isolate Yunnan (94.9\%). Conversely, HB24 had only 79.7 and $79.1 \%$ sequence identity with BB-AND and RL5, respectively. Detailed sequence similarity comparison between HB7/HB24 and various PVS isolates at the complete genome, the ORF, and the amino acid levels are summarized and presented in Supplementary Tables $\mathrm{S} 1$ and $\mathrm{S} 2$.

Consistent with the sequence similarity, two main clades were observed in a phylogenetic tree constructed using PVS HB7/HB24 and 10 available full length sequences of PVS from GenBank (Fig. 2). As anticipated, isolates PVS HB7 and PVS HB24 clustered with PVS ${ }^{\mathrm{A}}$ and $\mathrm{PVS}^{\mathrm{O}}$ groups, respectively. Moreover, in the $\mathrm{PVS}^{\mathrm{A}}$ clade, $\mathrm{PVS}$ HB7 and Brazilian isolate BB-AND sit more closely to each other than to Colombian isolate RL5, and in the $\mathrm{PVS}^{\mathrm{O}}$ clade, PVS HB24 clustered more closely with the North American isolates Id4106US and WaDef-US than with other isolates (Fig. 2). It is noteworthy that, although the Czech isolate Vltava grouped together with PVS ${ }^{\mathrm{O}}$ clade based on the complete genome sequence, it is a recombinant isolate whose genome was derived from $\mathrm{PVS}^{\mathrm{O}}$ (nt. 1 to 6,105 ) and PVS $^{\text {A }}$ (nt. 6,106 to $3^{\prime}$ end) (Duarte et al. 2012). In a phylogenetic tree constructed on the CP gene (nt.7,212 to 8,096), Vltava clustered with PVS $^{\mathrm{A}}$ strain group, consistent with the previous reports (Duarte et al.2012; Lin et al. 2014). Except for Vltava, all isolates described in Figure 2 exhibited the same phylogenetic relationship in a tree generated using $98 \mathrm{CP}$ gene sequences of PVS. Interestingly, the Colombian isolate RVC clustered in an independent branch distantly related to $\mathrm{PVS}^{\mathrm{O}}$ and $\mathrm{PVS}^{\mathrm{A}}$ based on both the complete genome sequences and CP genes of PVS isolates analyzed in this study (Fig. 2 and Supplementary Fig. S2). Indeed, the sequence identities between RVC and $\mathrm{PVS}^{\mathrm{A}} / \mathrm{PVS}^{\mathrm{O}}$ ware only $\sim 80.0 \%$, considerably lower than that within members in the respective clade. This analysis supports previous suggestion that RVC might represent a new PVS lineage (Gutiérrez et al. 2013).

Symptom development following inoculation to different plant species. To investigate the pathogenicity of the PVS isolates exhibiting molecular properties of PVS ${ }^{\mathrm{A}}$ (HB7) or PVS ${ }^{\mathrm{O}}$ (HB24), the isolates were mechanically inoculated onto $C$. quinoa. PVS HB7 not only induced chlorotic lesions on the inoculated leaves in $C$. quinoa, but also caused systemic symptoms including mottling on the upper uninoculated leaves (Fig. 3), indicating systemic infection in the plants. ELISA and RT-PCR test on both the inoculated and upper uninoculated leaves confirmed the infection (Table 3 and Supplementary Fig. S3, lanes 5 and 6). On the other hand, PVS HB24 only induced chlorotic lesions on the inoculated leaves but no noticeable symptoms on the upper uninoculated leaves (Fig. 3). No ELISA nor RT-PCR detectable level of PVS was found in these upper uninoculated leaves at $28 \mathrm{dpi}$ (Table 3), indicating no systemic infection with PVS HB24 in the plants. These results, together with molecular properties of the isolates, demonstrate that HB7 is a PVS ${ }^{\mathrm{A}}$ isolate whereas $\mathrm{HB} 24$ is a $\mathrm{PVS}^{\mathrm{O}}$ isolate. It is noteworthy that mixed inoculation with $\mathrm{HB} 7$ and HB24 led to symptoms resembling single infection with HB7 (Fig. 3) and only PVS ${ }^{\mathrm{A}}$ isolate was detectable by RT-PCR on the upper uninoculated leaves, although both $\mathrm{PVS}^{\mathrm{O}}$ and $\mathrm{PVS}^{\mathrm{A}}$ isolate were detected on the inoculated leaves.

Further serological (ELISA), molecular (RT-PCR), and C. quinoabased biological analysis of the samples that had been initially identified as $\mathrm{PVS}^{\mathrm{O}}, \mathrm{PVS}^{\mathrm{A}}$, or $\mathrm{PVS}^{\mathrm{O}}+\mathrm{PVS}^{\mathrm{A}}$ by RT-PCR assays were carried out. Field samples 9 and 29 exhibited identical molecular, serological, and biological reactions to PVS HB7 and PVS HB24, respectively (Table 3), whereas samples 1 and 12 showed indistinguishable serological and biological reactions to PVS HB7 although both $\mathrm{PVS}^{\mathrm{O}}$ and $\mathrm{PVS}^{\mathrm{A}}$ were present in the samples. Consistent with the mixed inoculation experiments with PVS $\mathrm{HB} 7$ and PVS HB24, $\mathrm{PVS}^{\mathrm{O}}$ was not detected in the upper uninoculated leaves at 28 dpi by RT-PCR.
Although no visible symptoms were observed in Solanum chacoense and potato cv. Shepody after mechanical inoculation with PVS HB7 and PVS HB24, the plants tested PVS-positive by ELISA, demonstrating that both isolates can infect the plants readily. Contrary to that in $S$. chacoense and potato cv. Shepody, no visible symptoms nor ELISA-detectable levels of PVS were observed in $N$. occidentalis and $N$. tobaccum cv. Samsun, indicating that neither isolate can infect these plants (Supplementary Table S3). Overall, PVS HB7 and PVS HB24 couldn't be distinguished based on the symptom and infection ability on these species/cultivars.

\section{Discussion}

The complete nucleotide sequence of the first $\mathrm{PVS}^{\mathrm{O}}$ isolate, Leona from Germany, was reported in 2005 (Matoušek et al. 2005). Recently, the complete genome sequence of the first $\mathrm{PVS}^{\mathrm{A}}$ isolate, BB-AND from Brazil, was characterized (Duarte et al. 2012). To date, all PVS isolates but RVC and Vltava fall into $\mathrm{PVS}^{\mathrm{O}}$ or $\mathrm{PVS}^{\mathrm{A}}$ strain groups (Duarte et al. 2012; Gutiérrez et al. 2013). Although different symptoms and infectivity on $C$. quinoa have been used as a bioassay tool to distinguish $\mathrm{PVS}^{\mathrm{O}}$ from $\mathrm{PVS}^{\mathrm{A}}$, the emergence of $\mathrm{PVS}^{\mathrm{O}-\mathrm{CS}}$, which infects $C$. quinoa systemically but is phylogenetically clustered closely to $\mathrm{PVS}^{\mathrm{O}}$, compromised the accuracy of $C$. quinoabased bioassay (Cox and Jones 2010). Moreover, bioassays are time consuming and unsuitable for large-scale testing. ELISA is another favorable option, but the two strains are serologically indistinguishable by available commercial antibody. In this study, an RT-PCR based method was developed to complement biological and serological methods for PVS strain/isolate differentiation. The efficacy and accuracy of the newly developed RT-PCR were confirmed by genome sequencing and biological assay on representative isolates as well as field samples. RT-PCR based strain-differentiation methods have been developed and widely employed to differentiate/genotype virus strain in various plant viruses such as PVY (Chikh Ali et al. 2010; Lorenzen et al. 2006; Nie and Singh 2002, 2003). The newly developed RT-PCR should provide a reliable means for effective detection and differentiation of different PVS strains including $\mathrm{PVS}^{\mathrm{O}}, \mathrm{PVS}^{\mathrm{A}}$, and their natural recombinant isolates such as Vltava, and thus can be used to monitor and index the strains in seed potatoes.

PVS $^{\mathrm{A}}$ generally causes more severe symptoms on potato plants than PVS $^{\mathrm{O}}$ does (Dolby and Jones 1987; Rose 1983; Slack 1983; Wardrop et al. 1989). Despite this general trend, the response of potato to PVS infection is likely to be cultivar dependent (Lin et al. 2014; Rose 1983), and the asymptomatic infection of cv. Shepody with PVS HB7 (PVS ${ }^{\mathrm{A}}$ ) and PVS HB24 $\left(\mathrm{PVS}^{\mathrm{O}}\right.$ ) should not be generalized to other potato cultivars. The reactions of different potato cultivars, especially those that are widely grown in different areas in China, to $\mathrm{PVS}^{\mathrm{A}}$ and $\mathrm{PVS}^{\mathrm{O}}$ need to be investigated for better management and control of the virus strains.

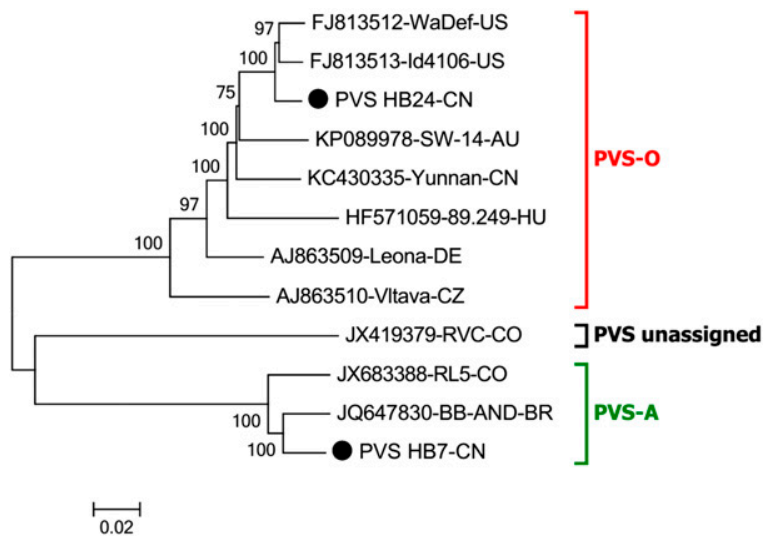

Fig. 2. Phylogenetic tree of Potato virus $S$ (PVS) isolates. The tree was constructed by MEGA6 based on the complete nucleotide sequences. Numbers at the nodes indicate the percentage of replicate trees in which the associated taxa clustered together in the bootstrap test $(1,000$ replicates), and only values $>70 \%$ are shown. The scale bar indicates numbers of nucleotide substitutions per site. The PVS isolates and associated GenBank accession numbers are shown. 
PVS $^{\mathrm{A}}$ was first reported in Peru (Hinostroza-Orihuela 1973) and subsequently in many other countries in Europe and America, including the Netherlands, New Zealand, the United Kingdom, Germany, Czech Republic, the United States, and Brazil (Duarte et al. 2012; Fletcher 1996; Lambert et al. 2012). In Asia, $\mathrm{PVS}^{\mathrm{A}}$ was only reported in India (Garg and Vinayak 2000) but not in other Asian countries including Syria and Iran (Chikh Ali et al. 2008; Salari et al. 2011). The finding of $\mathrm{PVS}^{\mathrm{A}}$ in China indicates the further spread of this strain worldwide. Similar to potato tuber necrosis strain of PVY $\left(\mathrm{PVY}^{\mathrm{NTN}}\right)$ as well other emerging potato viruses, $\mathrm{PVS}^{\mathrm{A}}$ is likely spread through multidirectional import/export of infected plant materials such as potato tubers. Although no report is available on the occurrence and distribution of PVS strains in
China, searching GenBank for PVS sequences found both $\mathrm{PVS}^{\mathrm{O}}$ and $\mathrm{PVS}^{\mathrm{A}}$-like sequences from several potato production provinces in China $\left(\mathrm{PVS}^{\mathrm{O}}\right.$ clade: KC430335, complete genome, Yunnan; AY512653, AY687337 and AJ889246, CP genes, Zhejiang; KF011268, KF011269, KF011279, and KF011280, CP genes, Guangxi; KC818634 and KC818635, CP genes, Shanxi; DQ315387, CP gene, Hebei; PVS clade: KF225470, CP gene, Guizhou; KF011270 to KF011278, CP genes, Guangxi). Among the $\mathrm{CP}$ sequences in the $\mathrm{PVS}^{\mathrm{A}}$ clade, nine (i.e., KF011270 to KF011278) were obtained by small RNA deep sequencing in samples collected from winter potato fields in Guangxi (Song et al. 2013). Taken together, it suggests that $\mathrm{PVS}^{\mathrm{A}}$ is present in other potato production areas in China. Nevertheless, more research that employs molecular, serological, and biological techniques, including
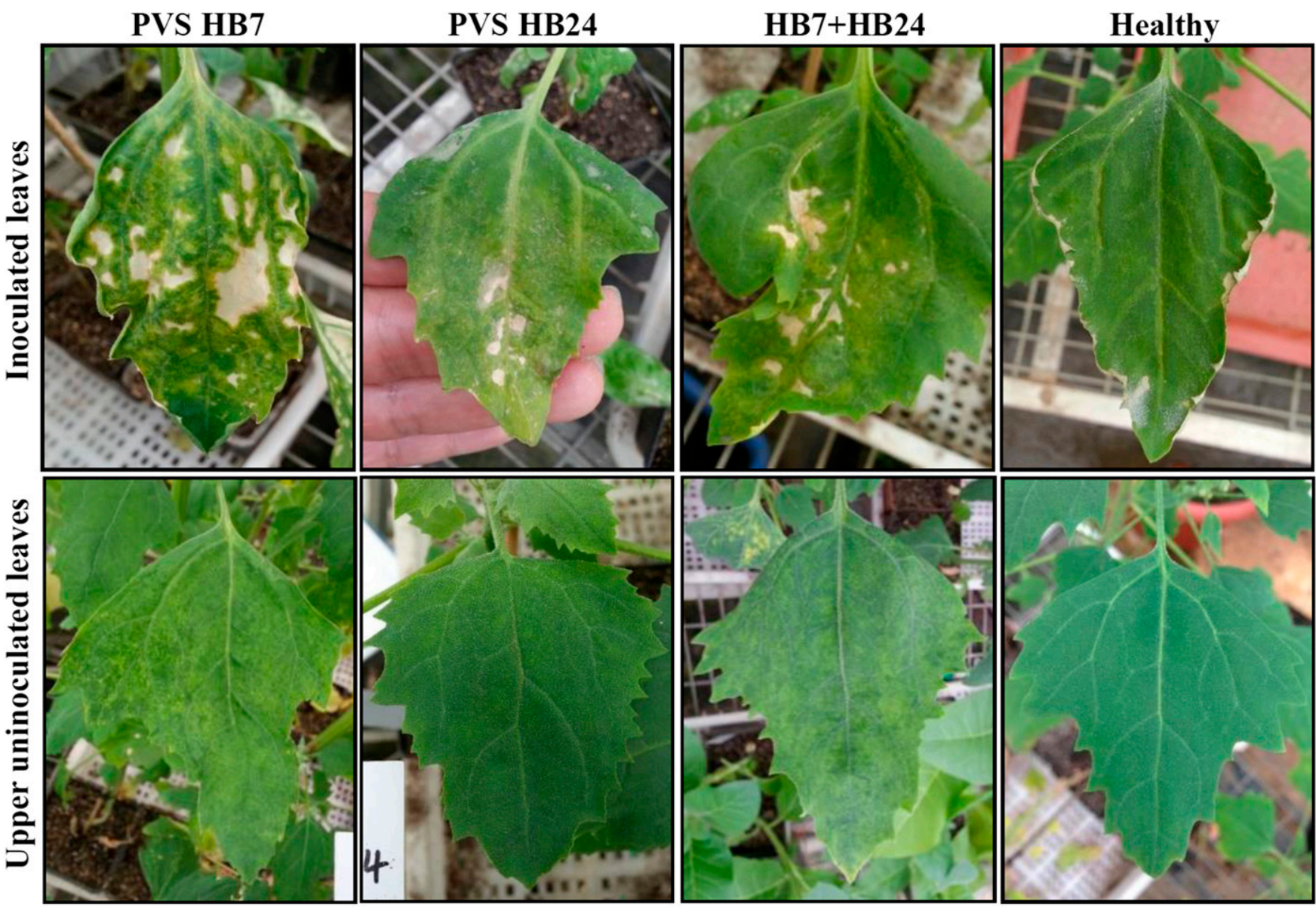

Fig. 3. Symptoms induced by PVS HB7 and PVS HB24 in Chenopodium quinoa. Top panel, inoculated leaves at 14 dpi. Bottom panel, upper uninoculated leaves at 28 dpi. Five plants each were inoculated mechanically singly with PVS HB7 or HB24 or mixedly with PVS HB7 + HB24. Identical results were obtained for each treatment. The experiment was repeated two times, and similar results were obtained. Pictures shown here were taken from the second experiment.

Table 3. RT-PCR, ELISA, and Chenopodium quinoa-based bioassay of Potato virus $S$ (PVS) samples collected in Hubei, China

\begin{tabular}{|c|c|c|c|c|c|}
\hline \multirow[b]{2}{*}{ PVS isolate/sample } & \multirow[b]{2}{*}{ RT-PCR assay ${ }^{a}$} & \multicolumn{2}{|c|}{ ELISA $^{\mathbf{b}}$} & \multicolumn{2}{|c|}{ Symptoms on $C$. quinoa } \\
\hline & & Inoculated leaves & Upper uninoculated leaves & Inoculated leaves & Upper uninoculated leaves \\
\hline PVS HB7 & $\mathrm{PVS}^{\mathrm{A}}$ & $0.452 \pm 0.051$ & $1.025 \pm 0.031$ & $\mathrm{CLL}^{\mathrm{c}}$ & Mottling \\
\hline PVS HB24 & $\mathrm{PVS}^{\mathrm{O}}$ & $0.957 \pm 0.073$ & $0.007 \pm 0.008$ & CLL & None \\
\hline Sample 9 & $\mathrm{PVS}^{\mathrm{A}}$ & $0.297 \pm 0.078$ & $1.028 \pm 0.026$ & CLL & Mottling \\
\hline Sample 29 & $\mathrm{PVS}^{\mathrm{O}}$ & $1.054 \pm 0.053$ & $0.006 \pm 0.004$ & CLL & None \\
\hline Sample 1 & $\mathrm{PVS}^{\mathrm{A}}+\mathrm{PVS}^{\mathrm{O}}$ & $0.589 \pm 0.079$ & $1.126 \pm 0.234$ & CLL & Mottling \\
\hline Sample 14 & $\mathrm{PVS}^{\mathrm{A}}+\mathrm{PVS}^{\mathrm{O}}$ & $0.481 \pm 0.039$ & $1.036 \pm 0.089$ & CLL & Mottling \\
\hline Mock & - & $0.002 \pm 0.002$ & $0.002 \pm 0.002$ & None & None \\
\hline
\end{tabular}

a Genotype of PVS samples was determined by CP and ORF1 based RT-PCR assays developed in this study.

${ }^{\mathrm{b}}$ Each value represents the mean standard deviation of five separate inoculated plants assayed by ELISA at 28 dpi; numbers in bold represent ELISA-positive values for that assay.

${ }^{\mathrm{c}} \mathrm{CLL}=$ chlorotic local lesions. Symptoms of inoculated leaves at $14 \mathrm{dpi}$ and upper uninoculated leaves at 48 dpi were presented. The experiment was repeated two times, and similar results were obtained. Results shown here were taken from the second experiment. 
the newly developed RT-PCR as well as C. quinoa-based bioassay, is needed to validate the sequence data.

\section{Acknowledgments}

The authors sincerely thank Yijuan Huang for assistance in potato sample collection and ELISA assay. This work was supported, in part, through grants from the National Natural Science Foundation of China (31101191 and 31571727) and Earmarked Fund for Modern Agro-industry Technology Research System (CARS-10-P08). This study formed part of a Master's degree in Agronomy for Jinghui Wang.

\section{Literature Cited}

Adams, M. J., Antoniw, J. F., Bar-Joseph, M., Brunt, A. A., Candresse, T., Foster, G. D., Martelli, G. P., Milne, R. G., and Fauquet, C. M. 2004. The new plant virus family Flexiviridae and assessment of molecular criteria for species demarcation. Arch. Virol. 149:1045-1060.

Čeřovská, N., and Filigarova, M. 1995. Specific detection of the Andean strain of potato virus S monoclonal antibodies. Ann. Appl. Biol. 127:87-93.

Chikh Ali, M., Maoka, T., and Natsuaki, K. T. 2008. The occurrence of potato viruses in Syria and the molecular detection and characterization of Syrian Potato virus $S$ isolates. Potato Res. 51:151-161.

Chikh Ali, M., Maoka, T., Natsuaki, K. T., and Natsuaki, T. 2010. The simultaneous differentiation of Potato virus $Y$ strains including the newly described strain PVY ${ }^{\text {NTN-NW }}$ by multiplex PCR assay. J. Virol. Methods 165:15-20.

Cox, B. A., and Jones, R. A. C. 2010. Genetic variability in the coat protein gene of Potato virus $S$ isolates and distinguishing its biologically distinct strains. Arch. Virol. 155:1163-1169.

Dolby, C. A., and Jones, R. A. C. 1987. Occurrence of the Andean strain of Potato virus $\mathrm{S}$ in imported potato material and its effects on potato cultivars. Plant Pathol. 36:381-388.

Duarte, P. S. G., Galvino-Costa, S. B. F., Ribeiro, S. R. R. P., and Figueira, A. R. 2012. Complete genome sequence of the first Andean strain of Potato virus $S$ from Brazil and evidence of recombination between PVS strains. Arch. Virol. 157:1357-1364.

Fletcher, J. D. 1996. Potato virus $\mathrm{S}^{\mathrm{A}}$ - characteristics of an isolate from New Zealand. N. Z. J. Crop Hortic. Sci. 24:335-339.

Foster, G. D. 1991. Molecular variation between ordinary and Andean strains of potato virus S. Res. Virol. 142:413-416.

Foster, G. D., and Mills, P. R. 1992. The 3'-nucleotide sequence of an ordinary strain of Potato virus S. Virus Genes 6:213-220.

Franc, G. D., and Banttari, E. E. 1996. Translocation and mechanical spread of a Minnesota isolate of potato virus $\mathrm{S}$ in potatoes. Am. Potato J. 73:123-133.

Garg, I. D., and Vinayak, H. V. 2000. Biological characterization, preservation and ultrastructural studies of Andean strain of potato virus S. Indian Phytopath. 53:256-260.

German, T. L. 2001. Potato virus S. Pages 67-68 in: Compendium of potato diseases, 2nd Ed., W. R. Stevenson, R. Loria, G. D. Franc, and D. P. Weingartner, eds. APS Press, St. Paul, MN.

Gutiérrez, P. A., Alzate, J. F., and Marín-Montoya, M. A. 2013. Complete genome sequence of a novel potato virus $\mathrm{S}$ strain infecting Solanum phureja in Colombia. Arch. Virol. 158:2205-2208.

Hinostroza-Orihuela, A. 1973. Some properties of potato virus S isolated from Peruvian potato varieties. Potato Res. 16:244-250.
Jones, R. A. C. 1981. The ecology of viruses infecting wild and cultivated potatoes in the Andean regions of South America. Pages 89-107 in: Pests, Pathogens and Vegetation. J. M. Thresh, ed. Pitman, London.

Kerlan, C. 2008. Potato Viruses. Pages 458-471 in: Desk Encyclopedia of Plant and Fungal Virology. B. W. J. Mahy and M. H. V. Van Regenmortel, eds. Elsevier Academic Press, Oxford, UK

Lambert, S. J., Scott, J., Pethybridge, S., and Hay, F. S. 2012. Strain characterization of Potato virus $S$ isolates from Tasmania, Australia. Plant Dis. 96:813-819.

Li, Y. Y., Zhang, R. N., Xiang, H. Y., Abouelnasr, H., Li, D. W., Yu, J. L., McBeath, J. H., and Han, C. G. 2013. Discovery and characterization of a novel Carlavirus infecting potatoes in China. PLoS One 8:e69255.

Lin, Y. H., Abad, J. A., Maroon-Lango, C. J., Perry, K. L., and Pappu, H. R. 2014 Molecular characterization of domestic and exotic potato virus $\mathrm{S}$ isolates and a global analysis of genomic sequences. Arch. Virol. 159:2115-2122.

Lorenzen, J. H., Piche, L. M., Gudmestad, N. C., Meacham, T., and Shiel, P. 2006 A multiplex PCR assay to characterize Potato virus $Y$ isolates and identify strain mixtures. Plant Dis. 90:935-940.

Mackenzie, D. J., Tremaine, J. H., and Stace-Smith, R. 1989. Organization and interviral homologies of the $3^{\prime}$-terminal portion of the potato virus S RNA. J. Gen. Virol. 70:1053-1063.

MacKinnon, J. P. 1974. Detection, spread, and aphid transmission of potato virus S. Can. J. Bot. 52:461-465.

Matoušek, J., Schubert, J., Ptáček, J., Kozlová, P., and Dědič, P. 2005. Complete nucleotide sequence and molecular probing of potato virus $S$ genome. Acta Virol. 49:195-205.

Mohapatra, S. S., Poole, R. J., and Dhindsa, R. S. 1987. Changes in protein patterns and translatable messenger RNA populations during cold acclimation of alfalfa Plant Physiol. 84:1172-1176.

Nie, X., and Singh, R. P. 2002. A new approach for the simultaneous differentiation of biological and geographical strains of Potato virus $Y$ by uniplex and multiplex RT-PCR. J. Virol. Methods 104:41-54.

Nie, X., and Singh, R. P. 2003. Specific differentiation of recombinant PVY ${ }^{\mathrm{N}: \mathrm{O}}$ and PVY ${ }^{\text {NTN }}$ strains by multiplex RT-PCR. J. Virol. Methods 113:69-77.

Rose, D. G. 1983. Some properties of an unusual isolate of potato virus S. Potato Res. 26:49-62.

Salari, K., Massumi, H., Heydarnejad, J., Pour, A. H., and Varsani, A. 2011. Analysis of Iranian Potato virus $S$ isolates. Virus Genes 43:281-288.

Singh, R. P., McLaren, D. L., Nie, X., and Singh, M. 2003. Possible escape of a recombinant isolate of Potato virus $Y$ by serological indexing and methods of its detection. Plant Dis. 87:679-685.

Slack, S. A. 1983. Identification of an isolate of the Andean strain of potato virus $S$ in North America. Plant Dis. 67:786-789.

Song, J., Meng, J., Zou, C., Li, P., Wang, Z., and Chen, B. 2013. Identification of viruses from potato planted in winter in Guangxi by small RNA deep sequencing. Scientia Agric. Sin. 46:4075-4081 (in Chinese).

Tamura, K., Stecher, G., Peterson, D., Filipski, A., and Kumar, S. 2013. MEGA6: Molecular Evolutionary Genetics Analysis version 6.0. Mol. Biol. Evol. 30: 2725-2729.

Wang, B., Ma, Y., Zhang, Z., Wu, Z., Wu, Y., Wang, Q., and Li, M. 2011. Potato viruses in China. Crop Prot. 30:1117-1123.

Wardrop, E. A., Gray, A. B., Singh, R. P., and Peterson, J. F. 1989. Aphid transmission of potato virus S. Am. Potato J. 66:449-459. 